\title{
Vitamin C Supplementation in the Elderly : A 17-month Trial in an Old Persons' Home
}

\author{
J. ANDREWS,* M.D. ; M. LETCHER, $†$ M.B., M.C.PATH., D.C.H.; M. BROOK, $\ddagger$ B.SC., PH.D.
}

\begin{abstract}
Cummary : Seventeen months' supplementation of the $\checkmark$ diet with vitamin $C$ in elderly residents in an old persons' home failed to show any changes in sublingual lesions, which on histological examination proved to be aneurysmal dilatations of the venules. Nine months' supplementation of $\mathbf{4 0}$ to $80 \mathrm{mg}$. daily of vitamin C was necessary before the white-cell vitamin levels reached that found in younger people. There was a marked individual variation in response.
\end{abstract}

\section{Introduction}

In recent years attention has been drawn to the possible existence of subclinical malnutrition among the elderly in Great Britain. Andrews et al. (1966) reported a significant fall in the white cell vitamin-C concentrations in the elderly during the winter, and we confirmed the work of Kataria et al. (1965), which showed that the vitamin-C status of elderly residents in institutions was often considerably lower than in those living at home. Together with Allen et al. (1967) we showed a sex difference in vitamin-C levels in the elderly and this has been found to be even more definite in younger people (Brook and Grimshaw, 1968).

Taylor (1966) originally suggested that there was a possible connexion between "senile purpura" and lesions that he described as "sublingual petechial haemorrhages" and chronic vitamin-C deficiency. Nevertheless, Andrews and Brook (1966) confirmed the earlier work of Tattersall and Seville (1950), which showed that low vitamin-C status and "senile purpura"

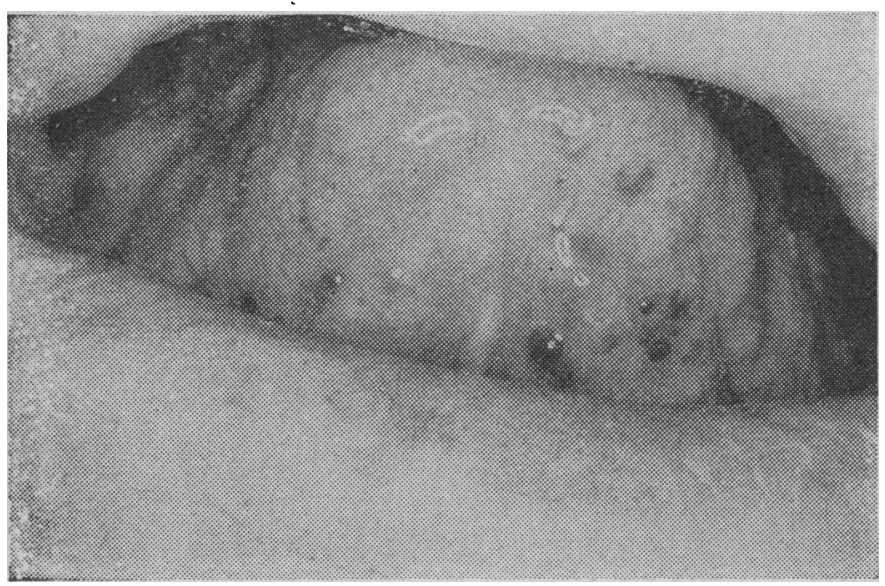

FIG. 1.-Photograph of sublingual lesions.

were not related. The sublingual lesions referred to by Taylor (Fig. 1) had been originally described by Mendes da Costa and Cremer from Amsterdam (1930) and later by Bean (1952). The former described the lesions as "grains resembling caviar under the tongue." They also described their histological findings in addition to suggesting that the lesions were due to in-

- Consultant Physician to the Geriatric Service, West Middlesex Hospital, Isleworth.

+ Assistant Pathologist, Bland-Sutton Institute of Pathology, the Middlesex Hospital, London W.1.

‡ Basic Research Department, Beecham Products U.K. creased venous pressure. Bean (1952) suggested that the lesions in patients over 70 were more common in women, but our impression from the surveys on the elderly over 60-both in hospitals and old persons' homes-was that the lesions are perhaps two or three times more common in men.

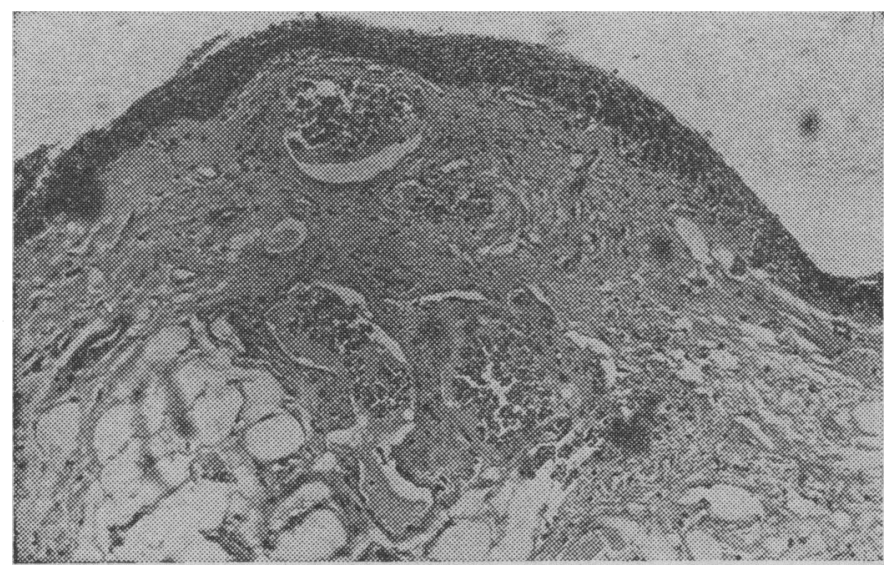

Fig. 2.-Histological specimen of sublingual lesion.

\section{Findings at Necropsy}

A histological examination of 17 necropsy specimens-13 from men and four from women-and one surgical biopsy specimen was performed. The material was fixed in $10 \%$ formol saline, routinely processed, and paraffin sections were stained with Ehrlich's haematoxylin and eosin. Sections were also taken from apparently normal areas and from a 39-yearold man for comparison.

At necropsy the lesions were similar to those seen in life, though rather smaller, and these presented as purple, slightly raised nodules with a sharp edge underneath the intact sublingual epithelium. They varied from 1 to $3 \mathrm{~mm}$. in diameter. Identical lesions were also found on the posterosuperior surface of the tongue near its roots, but nowhere else. In every case the lesions were intact, thin-walled, dilated small blood vessels lying in the thin layer of connective tissue underneath the sublingual squamous epithelium. These vessels contained blood, and a few showed antemortem thrombus formation. Most of the lesions appeared to be single dilated vessels, but a few, including the biopsy specimen, showed several (two or four) small vessels lying near each other (Fig. 2). The vessels had a distinct endothelial lining and a very thin wall of connective tissue in which no muscular or elastic elements were found. The vessels ranged from 0.5 to $4 \mathrm{~mm}$. in diameter, but the majority were 1 to $2 \mathrm{~mm}$. in diameter.

The walls of the largest $(4 \mathrm{~mm}$.) vessels were slightly thicker and showed a few incomplete septa partly dividing them-an appearance suggestive of a vessel with a tortuous course. Sections taken from apparently normal areas showed similar but flattened small vessels running parallel to the surface and rather nearer the muscle coats. The structure of the vessel walls was consistent with that of dilated capillaries or of 
venules, but the size of the walls suggested that the vessels were more likely to be venules. The tissue surrounding the vessels showed no evidence of haemorrhage, haemosiderin formation, or localized inflammatory reaction, all of which are found in association with true petechiae due to scurvy or other causes. The connective tissue did not differ from that found in other parts of the tongue or in the control case. (The biopsy specimen showed diffuse extravasated red cells throughout the specimen in addition to dilated vessels. The lesion was known to have been present for some months, and since there was no sign of altered blood pigment we believe that this extravasation was secondary to biopsy and not a primary feature.)

\section{Clinical Studies}

During a recent 17 -month period we carried out the following investigations on elderly residents in an old persons' home : (1) examination for these sublingual lesions, (2) measurement of white cell vitamin-C concentration (for any given plasma level of vitamin $C$ the white-cell level varies considerably, and when assessing tissue state the white-cell investigation is therefore the measurement of choice (Andrews and Brook, 1968)), and (3) observations on the residents' diets at regular intervals. These routine investigations were carried out every three to four months.

Selected residents over 65 years of age who had been in the old persons' home for longer than three months were divided into three treatment groups. The first group was not given vitamin-C supplement, but the second group was given $40 \mathrm{mg}$. daily and the third group $80 \mathrm{mg}$. daily.

Table I shows in parentheses the number in the trial who had sublingual lesions.

\section{TABLE I}

\begin{tabular}{lll|l|l|l}
\hline & & & Total & Men & Women \\
\hline Initial No. & $\cdots$ & $\cdots$ & $59(35)$ & $33(21)$ & $26(12)$ \\
Surviving No. & $\cdots$ & $\cdots$ & $36(19)$ & $18(12)$ & $18(7)$ \\
Survivors (\%) & $\cdots$ & $\cdots$ & 61 & 54.5 & 69
\end{tabular}

Death was the only reason for withdrawal from the trial except in the case of two residents who were uncooperative. A further resident was transferred to a home for the blind late in the trial but continued to be observed with the others.

\section{Results}

Though we previously found a significantly higher white cell vitamin-C concentration in the old people who were without these lesions (Andrews and Brook, 1966) than in those with them, we could show no consistent reduction in the incidence or intensity of the lesions at the end of the 17 months' supplementation of the diet with vitamin $C$.

Table II shows the change in the sublingual lesions in survivors according to sex.

\begin{tabular}{|c|c|c|c|c|c|}
\hline & & & Decrease & No Change & Increase \\
\hline \multicolumn{6}{|c|}{ Untreated } \\
\hline \multirow[t]{2}{*}{$\begin{array}{l}\text { Men } \\
\text { Women }\end{array}$} & .. & \begin{tabular}{l|}
. \\
$\cdots$
\end{tabular} & $\begin{array}{l}2 \\
1\end{array}$ & $\begin{array}{l}5 \\
3\end{array}$ & $\begin{array}{l}1 \\
1\end{array}$ \\
\hline & Total ... & $\ldots$ & 3 & 8 & 2 \\
\hline \multicolumn{6}{|c|}{ Treated (40 or 80 mg. of Vitamin C Daily) } \\
\hline $\begin{array}{l}\text { Men } \\
\text { Women }\end{array}$ & .. & $\therefore$ & $\begin{array}{l}2 \\
1\end{array}$ & $\begin{array}{l}8 \\
7\end{array}$ & $\frac{1}{4}$ \\
\hline & Total ... & $\bar{\ldots}$ & 3 & 15 & 5 \\
\hline
\end{tabular}

Though no convincing statistical evidence of seasonal fluctuation was found, one of us (M. L.) noted that these lesions occurred frequently in winter months but only occasionally in summer. In our opinion Taylor's (1966) hypothesis that these sublingual lesions might be a sign of chronic vitamin- $C$ deficiency could be tested only by a lengthy trial of supplementing the diet with vitamin $C$, which included adequate clinical observation and biochemical control as already described.

\section{Discussion}

In his interesting review paper on Campbell De Morgan's spots-a similar vascular anomaly-Bean (1953) stated that " in academic circles there is an understandable shyness in admitting we are wrong." We would like to emphasize that we now think it is very improbable that these lesions and vitamin-C deficiency are related.

The mean concentration of ascorbic acid in the white blood cells of those who survived the whole period of vitamin-C supplementation is shown in Fig. 3. Before supplementation a very low initial white cell vitamin-C concentration was observed in the residents compared with the average level of $26 \mu \mathrm{g} . / 10^{8}$ white cells for younger normal people as reported by Calder et al. (1963). Lower levels were found in the old persons' home under study than previously arnong elderly people living at home. Kataria et al. (1965) reported an average level in those at home of $26 \mu \mathrm{g} . / 10^{3}$ cells, while Andrews et al. (1966) found an average level of $18.5 \mu \mathrm{g} . / 10^{8}$ cells.

The low levels of vitamin $\mathrm{C}$ recorded among the elderly in institutions may be caused at least partially through institutionalized cooking ; but not the low levels found in the elderly at home, which may not be related entirely to quantitative and/ or qualitative deficiencies in their diet. Although Ahlborg (1946) carried out some work on vitamin C renal threshold levels among the young, further studies are required concerning the elderly.

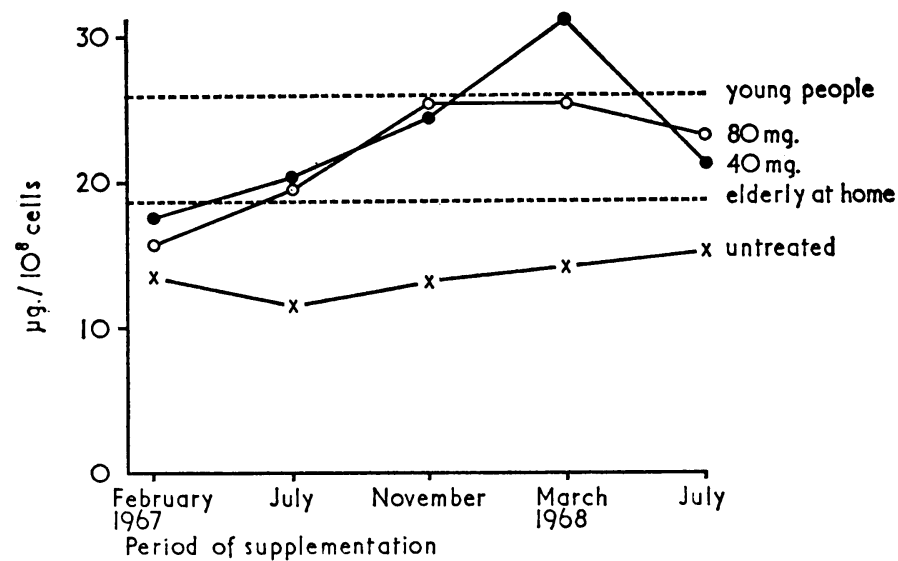

FIG. 3.- Mean concentration of ascorbic acid in white cells during 17-month period.

While the amount of added vitamin $\mathrm{C}$ was considerably above the British Medical Association's (1950) recommended daily allowance of $30 \mathrm{mg}$. for adults-though the U.S.A. National Academy of Sciences now recommends $60 \mathrm{mg}$. daily for men and $55 \mathrm{mg}$. for women (Food and Nutrition Board, National Research Council U.S.A., 1968)-the rate of increase in the whitecell concentration of vitamin $\mathrm{C}$ was slow. The white-cell concentration of vitamin $\mathrm{C}$ of one person, which had taken six months to reach $25 \mu \mathrm{g} . / 10^{8}$ on a supplement of $80 \mathrm{mg}$. daily, fell to its starting level of $11 \mu \mathrm{g} . / 10^{8}$ within three months of ceasing the supplement. There was a puzzling decline in vitamin-C levels in the white cells towards the end of the trial. We have no satisfactory explanation for this, and all our inquiries have confirmed that fruit juice containing vitamin $\mathrm{C}$ was being taken. A regular check of the institutional diet confirmed that there were no major changes in its vitamin-C content during the trial. 
Fig. 4 shows that there was a definite variation of individual response within the supplemented group. It is interesting to note that the percentage increase in the white blood cell concentration varied from $5 \%$ to over $100 \%$ for individuals whose initial concentration was between 12.5 and $15 \mu \mathrm{g} . / 10^{8}$.

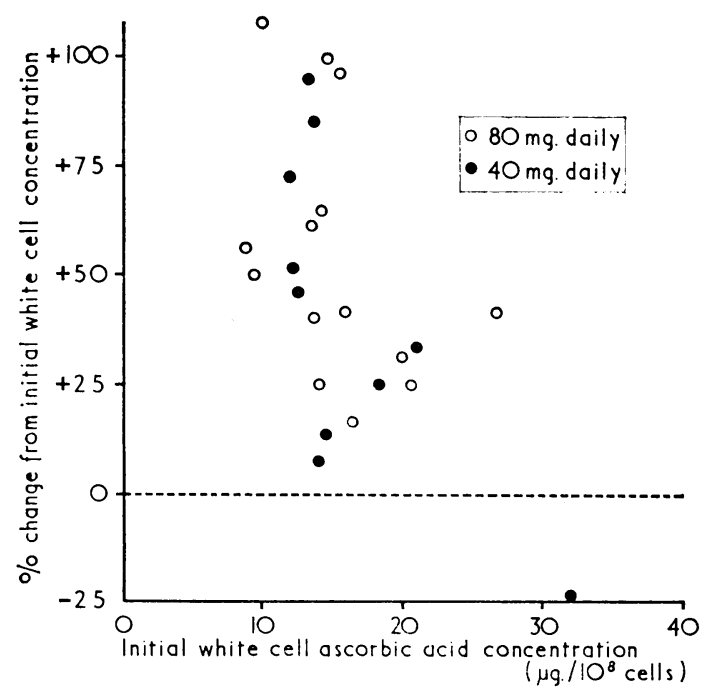

FIG. 4.-Individual response to vitamin C supplement for 17 months.

One might expect that the people most deficient in vitamin $\mathrm{C}$ would display the greatest response, but this is not shown here. Individual dietary investigation failed to show any change in personal dietary habits sufficient to account for these considerable individual variations. These latter must be taken into account if recommendations are to be made for any nutritional targets in the elderly. Moreover, as a result of animal studies Williams and Deason (1967) have claimed that there is a substantial individual variation in vitamin $\mathrm{C}$ requirements.
We would like to acknowledge the help we have received from workers in various disciplines. Mrs. M. A. Allen for undertaking the difficult task of reviewing the residents' diet at regular intervals, Mr. I. Cour Palais, Consultant Surgeon, West Middlesex Hospital, for taking a biopsy section from a tongue, Dr. G. Muheim of Basle and Dr. S. K. Bose of the West Middlesex Hospital for helping one of us take blood samples, Mr. D. Vinten of the photographic department at the West Middlesex Hospital for preparing the photomicrograph, and Miss S. Robinson, Medical Artist at the West Middlesex Hospital, for preparing the diagrams.

\section{REFERENCES}

Ahlborg, N. G. (1946). Acta Physiologica Scandinavica, 12, Suppl. No. 36.

Allen, M. A., Andrews, J., and Brook, M. (1967). Nutrition (London), 21, 136.

Andrews, J., and Brook, M. (1966). Lancet, 1, 1350

Andrews, J., and Brook, M. (1968). Gerontologia Clinica, 10, 128.

Andrews, J., Brook, M., and Allen, M. A. (1966). Gerontologia Clinica, 8, 257 .

Bean W. B. (1952). Transactions of the American Clinical and Climatological Association, 64, 40

Bean, W. B. (1953). Transactions of the Association of American Physicians, 66, 240 .

British Medical Association (1950). Report of the Committee on Nutrition. London.

Brook, M., and Grimshaw, J. J. (1968). American fournal of Clinical Nutrition, 21, 1254.

Calder, J. H., Curtis, R. C., and Fore, H. (1963). Lancet, 1, 556.

Food and Nutrition Board, National Research Council U.S.A. (1968). Recommended Dietary Allowances, 7th ed. Washington, Government Printing Office.

Kataria, M. S., Rao, D. B., and Curtis, R. C. (1965). Gerontologia Clinica, 7, 189.

Mendes da Costa, S., and Cremer, G. (1930). Dermatologische Wochenschrift, 91, 1206 .

Tattersall, R. N., and Seville, R. (1950). Quarterly fournal of Medicine, 19, 151.

Taylor, G. (1966). Lancet, 1, 926.

Williams, R. J., and Deason, G. (1967). Proceedings of the National Academy of Sciences, 57, 1638 .
Duchenne muscular dystrophy is characterized by progressive muscle weakness beginning in early childhood and affecting first the pelvic girdle musculature and later the pectoral girdle musculature. The child becomes confined to a wheelchair by about the age of 10 and dies at about 20, from either respiratory infection or cardiac failure. The condition mainly affects boys, and in most cases is inherited as an X-linked recessive trait, being transmitted by female carriers who are usually healthy but very occasionally may have muscle weakness (Emery and Walton, 1967).

Cardiac muscle as well as skeletal muscle is affected in Duchenne muscular dystrophy as evidenced by the frequent occurrence of arrhythmias and persistent tachycardia, and sudden death from cardiac failure is common. The histological findings in cardiac muscle resemble those found in skeletal muscle (variation in fibre size, hyalinization, fatty infiltration, and connective-tissue proliferation) and have been described 